\title{
Review
}

Zhenhui Li, Ke Xu*, and Yusheng Pan

\section{Recent development of Supercapacitor Electrode Based on Carbon Materials}

https://doi.org/10.1515/ntrev-2019-0004

Received Jan 21, 2019; accepted Mar 15, 2019

\begin{abstract}
Supercapacitor has gained significant attention due to its fast charging/discharging speed, high power density and long-term cycling stability in contrast to traditional batteries. In this review, state-of-the-art achievements on supercapacitor electrode based on carbon materials is summarized. In all-carbon composite materials part, various carbon materials including graphene, carbon nanotube, carbon foam and carbon cloth are composited to fabricate larger specific surface area and higher electrical conductivity electrodes. However, obstacles of low power density as well as low cycling life still remain to be addressed. In metal-oxide composites part, carbon nanotube, graphene, carbon fiber fabric and hollow carbon nanofibers combine with $\mathrm{MnO}_{2}$ respectively, which sig nificantly address drawbacks of all-carbon material electrodes. Additionally, $\mathrm{TiO}_{2}$ is incorporated into graphene electrode to overcome the low mechanical flexibility of graphene. In organic active compounds part, conducting polymers are employed to combinate with carbon materials to fabricate high specific capacitance, long-term thermal stability and outstanding electroconductivity flexible textile supercapacitors. In each part, innovation, fabrication process and performance of the resulting composites are demonstrated. Finally, future directions that could enhance the performance of supercapacitors are discussed.
\end{abstract}

Keywords: supercapacitor, electrode, carbon materials, composite

\footnotetext{
*Corresponding Author: Ke Xu: School of Information \& Control Engineering, Shenyang Jianzhu University, Shenyang, China; Email: xksky1234@163.com

Zhenhui Li, Yusheng Pan: School of Information \& Control Engineering, Shenyang Jianzhu University, Shenyang, China Zhenhui Li and Ke Xu contributed equally to this work
}

๑ Open Access. (C) 2019 Z. Li et al., published by De Gruyter. (CC) BY License

\section{Introduction}

With the rapid growth of global economy, the loss of fossil fuels and the increasing environmental pollution, there is an urgent need for highly efficient energy storage devices. In this context, electrochemical capacitor, so-called supercapacitor (SC), which is one of the most promising energy storage devices, recently attracts considerable attention owing to its high power density, fast charge-discharge, and long service life [1-6].

Electrode material, which is the corresponding key for SCs, plays an important role in improving the performance of SCs [7-10]. Amongst various candidates, Carbons have been widely employed for fabricating SC electrodes [11-13]. Carbons are such electronically conductive solids that possess satisfactory corrosion resistance, low density, excellent stability and low cost $[14,15]$. In addition, the porosity and morphology of carbons can be simply designed by using oxidizing agents at warm processes, which is called activation. These formed highly porous materials had a large surface area up to $2000 \mathrm{~m}^{2} \cdot \mathrm{g}^{-1}$ [16-18]. The control of porosity in supercapacitors can not only obtain a high specific capacity of ion adsorption, but also measure the diffusion rate of ions in and out of the pores during the charge/discharge processes.

As one member of carbon materials, carbon nanotube (CNT) reveals high electrical conductivity, great electron transport and electrolyte accessibility. As a result, CNT is considered as a promising material to fabricate electrode material. Graphene is another attractive electrode material because of its outstanding conductivity and large specific surface area [19-22]. Nonetheless, low volumetric capacitance, hard fabrication and high costs for commercial production of these carbon materials remain stumbling blocks for making further breakthroughs in excellent performance supercapacitors. With respect to this, much work has been carried out on synthesizing reduced graphene oxide ( $\mathrm{rGO}$ ). One of the most extensive routes to obtain rGO flakes is the Hummers' method [23]. In this method, first, graphite is oxidized in aqueous medium, then, oxydic graphite was reduced/exfoliated using, as an example, chemical [14-28], thermal [29], hydrothermal [30], electro- 
chemical [31, 32] or microwave-assisted reduction means [33].

However, the introduction of $\mathrm{rGO}$ cannot solve all issues mentioned above. composites that combining carbon nanomaterials with micro-sized carbon particles/substrates as well as other moieties that contain redox activity can probably address these obstacles [34]. When inserting CNT between graphene nanosheets (GNs), GNs can linked into a stable, thus enhances the surface area of electrolyte ions in contrast to pure rGO. Moreover, CNT can consociate with rGO, which not only offers conductive pathways for electron transport but also cuts down the internal resistance inside the electrode [35-38].

As a matter of fact, it's undeniable that all-carbon composite materials exist the problems of lower power density as well as lower cycling life. A satisfactory strategy to address these handicaps is to incorporate finely dispersed pseudocapacitive metal oxides such as $\mathrm{MnO}_{2}$ and $\mathrm{TiO}_{2}$ into a carbon matrix. $\mathrm{MnO}_{2}$ is considered as one of the most promising metal oxides owing to its simple synthesis technology, low cost and outstanding electrochemical properties [39]. Combining $\mathrm{MnO}_{2}$ with highly electrically conductive carbon matrices such as graphene [40], CNTs [41] and hollow carbon nanofibers [42] to increase pseudocapacitive behavior has stimulated extensive research. Here, carbon materials are utilized as scaffolds, and $\mathrm{MnO}_{2}$ nanostructures are deposited in situ on the surfaces of carbon materials. This innovational design has been validated to reduce the electronic/ion transport way, offer larger surface area with extensive active sites for fast Faradic reactions on electrode/electrolyte interfaces, in a way, realize the enhancement of electrochemical performance [43]. $\mathrm{TiO}_{2}$ is also widely investigated owing to its abundance, low cost, long-term thermodynamic stability, photostability, nontoxic, excellent pseudocapacitance behavior and easy fabrication [44]. Unfortunately, its low conductivity greatly influences the specific capacitance of $\mathrm{TiO}_{2}$ electrodes [45]. Incorporating $\mathrm{TiO}_{2}$ into graphene electrodes can help address the obstacles of low conductivity of $\mathrm{TiO}_{2}$ and low mechanical flexibility of graphene, respectively. Herein, $\mathrm{TiO}_{2}$ usually acts as an additive for carbon materials, especially for graphene [46].

Conducting polymer, especially polyaniline (PANI), has captured intensive attention due to its low price, convenient synthesis, high pesudocapacitance and excellent chemical doping/undoping [47-50]. To overcome some of the drawbacks of pure PANI [51], PANI is usually employed to combine with carbon materials to fabricate flexible textile supercapacitors with excellent performance [52], including enhancing specific capacitance, increasing thermal stability, improving electroconductivity and so on. As an example, Lu et al. fabricated a PC/CNTs/PANI nanocomposite, this composite held the specific capacitance of $1090 \mathrm{~F} \cdot \mathrm{g}^{-1}$ and revealed a specific energy density of 97 $\mathrm{Wh} \cdot \mathrm{kg}^{-1}[53]$.

Many reviews of supercapacitor electrode materials have been reported. However, they usually focus on one single material, such as graphene, $\mathrm{CNT}, \mathrm{MnO}_{2}$ and so on. With the booming development of supercapacitors, one material can not satisfy the demand of supercapacitors, and studies of combinations with different materials need to be urgently intensified. In this work, compositions that use at least one carbon basic and one active basic are demonstrated.

\section{All-carbon composite capacitors}

Kim et al. [54] fabricated 2D porous graphene/CNT networks with vertically aligned honeycomb structures, the resulting networks could be used to fabricate stretchable supercapacitors electrodes. The schematic illustration of the fabrication process was shown in Figure 1. Here, reentrant structures were synthesized via a directional crystallization process followed by a radial compression. In contrast to conventional frameworks, reentrant structures, which were inwardly protruded frameworks in porous networks, offered fascinating structure-assisted stretchability, like accordion and origami structures. In addition, the resulting structures revealed great conductivities under biaxial stretching conditions. The 2D auxetic cellular and vertically aligned structures overcome the tradeoff among conductivity, ion-accessible surface area and tensile properties of electrodes and realize the fabrication of highperformance stretchable supercapacitors, which is essential to realize implantable and epidermal electronics.

Díez et al. [55] demonstrated an easy method for the preparation of a partially reduced graphene oxide/carbon nanotube (prGO-CNT) self-standing binder-free film. This film was prepared from a mixture of GO and CNTs by hydrothermal treatment at $210^{\circ} \mathrm{C}$ to generate a hydrated selfassembled composite, after compressing, this composite finally required high density with tuned areal carbon loading. In contrast to CNT-free electrode, due to the incorporation of a handle of CNTs (only $2 \mathrm{wt} \%$ ), prGO-CNT film had a greatly enhancement in capacitance retention at high current densities and the stability during cycling, this improvement was beneficial to supercapacitors with high mass loading electrodes. Moreover, this film obtained high volumetric capacitance and excellent capacitance retention (250 and $200 \mathrm{~F} \mathrm{~cm}^{-3}$ at 1 and $10 \mathrm{~A} \cdot \mathrm{g}^{-1}$, respectively), 

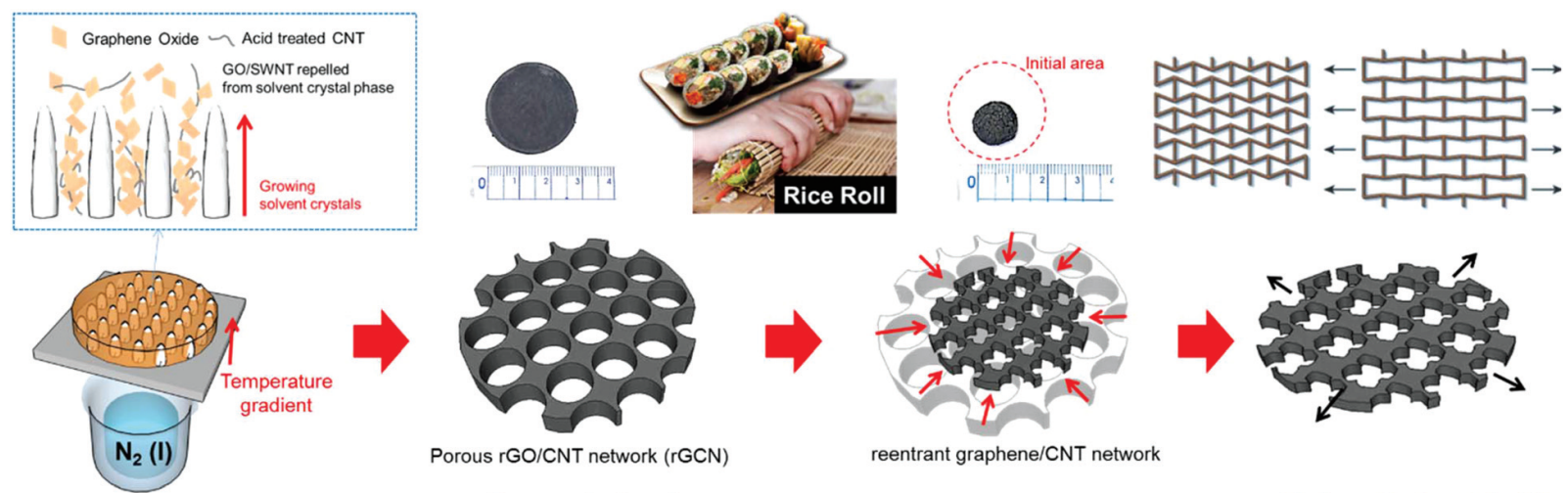

Freeze drying \&

Directional Crystallization

Chemical Reduction

reentrant graphene/CNT network

Radial Compression
2D Auxetic Stretchable RGO/CNT Electrode

Figure 1: Schematic illustration of the fabrication process of two-dimensional (2D) auxetic reentrant graphene/CNT networks for omnidirectionally stretchable supercapacitor electrodes based on a directional freezing and radial compression process
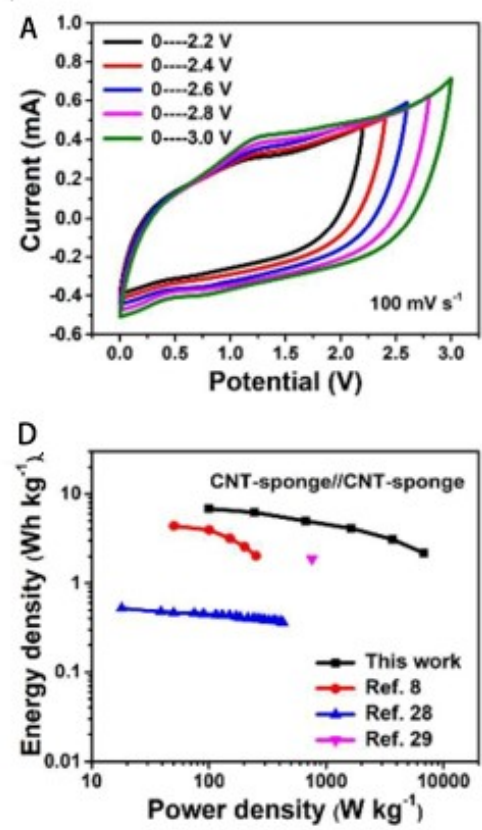

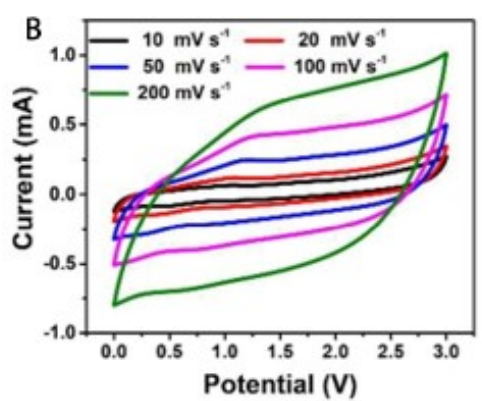

$\mathrm{E}$

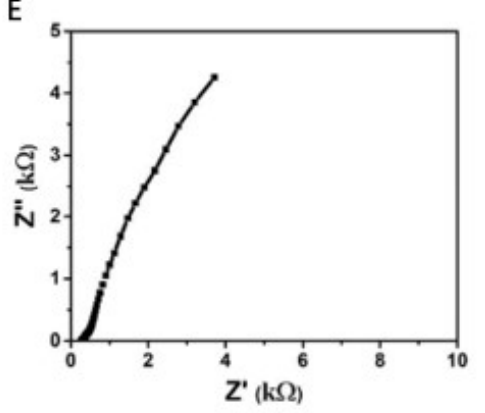

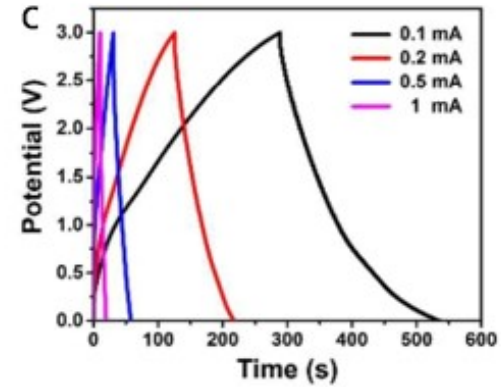

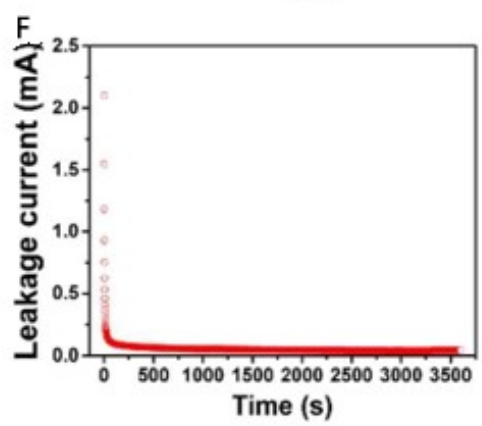

Figure 2: Electrochemical performances of the CNT-aerogel//CNT-aerogel FSC device. (A) CV curves measured in different potential window at $100 \mathrm{mV} \cdot \mathrm{s}^{-1}$. (B) CV curves in the voltage window of $0-3 \mathrm{~V}$ at a scan rate range of 10 to $200 \mathrm{mV} \cdot \mathrm{s}^{-1}$. (C) GCD curves at different current densities in the same voltage window of 0-3 V. (D) Ragone plots comparing the energy density and power density with previously reported studies. (E) Nyquist plot in the frequency range of $100 \mathrm{kHz}$ to $10 \mathrm{mHz}$. (F) Leakage current curves of the FSC device charged to floating potential of $2.5 \mathrm{~V}$ and kept for $1 \mathrm{~h}$

which make it a promising electrode material for supercapacitors.

Li et al. [56] demonstrated a method to fabricate a novel fibrous CNT-aerogel with large specific surface area, high mechanical strength, and admirable electrical conductivity by electrochemical activation and freeze-drying and employed it as fiber supercapacitors (FSCs). In the normal works, the enhancement of energy density was mainly realized by increasing the specific capacitance of the elec- trode, such as compounding with pseudocapacitive materials. Here, the introduction of ionogel electrolyte made the CNT-aerogel//CNT-aerogel FSC store energy at the interface between the electrode surface and the electrolyte, instead of by electrochemical reactions. This innovation made its power density 1 2 orders of magnitude higher than previous reported FSCs (Figure 2). The higher energy density had been close to the level of lithium-ion batteries and the power density had reached the highest value of 
Table 1: Comparison of energy density and power density of different carbon materials. Values were obtained from the respective references

\begin{tabular}{lccc}
\hline Electrode material & $\begin{array}{c}\text { Energy } \\
\text { density } \\
(\mathrm{Wh} \\
\left.\mathrm{Kg}^{-1}\right)\end{array}$ & $\begin{array}{c}\text { Power } \\
\text { density } \\
(\mathrm{Wh} \\
\left.\mathrm{Kg}^{-1}\right)\end{array}$ & \\
\hline Carbon foam/CNT & 28 & 3700 & This work \\
Active Carbon/CNT & 0.016 & 14.4 & {$[63]$} \\
Graphene/CNT/Nickel & 19.24 & 5398 & {$[64]$} \\
foams & & & \\
CNT/Carbon cloth & 5.73 & 44 & {$[65]$} \\
Graphene/MnO2/CNT & 3.2 & 1280 & {$[66]$} \\
MnO2/CNT/Graphene & 29 & 1200 & {$[67]$} \\
\hline
\end{tabular}

PSCs. Additionally, due to the non-volatility, high thermal stability of ionogel electrolyte, the assembled FSCs could run normally at a working temperature window from $0^{\circ} \mathrm{C}$ to $80^{\circ} \mathrm{C}$. All of these reveal CNT-aerogel can be a favorable candidate for FSCs and the synthetic FSC is a favorable power source for flexible electronics.

Carbon foam (CF), a sponge-like rigid carbon material which possesses a large surface area with an open cell wall structure. Due to CF's attractive properties like high chemical stability, excellent electrical conductivity, outstanding corrosion resistance and high mechanical strength, CF has been triggered in order to develop long-life and highperformance electrodes for responding to the increasing demand of energy storage shielding [57-61]. Dang et al. [62] fabricated a long-life and high-performance CF/CNT electrode material by incorporating CNTs with different length (chemical vapor deposition) on a hierarchically 3D $\mathrm{CF}$, this assembly could collect current without adding any binders or conducting additives. Comparison of energy density as well as power density of different carbon materials was demonstrated in Table 1 , which revealed $\mathrm{CF} / \mathrm{CNT}$ materials were the best among pure CNT and CF materials. Superiority of this composite was correlated with the synergistic effect of combining CF and CNT together. This combination suggests a new method for producing electrode based on carbon material for energy storage.

Carbon cloth (CC) is such a substrate that can offer simple ionic intercalation of the electrolyte and a number of fast electro-transport pathways without adding polymer binder [68]. Owing to those favorable advantages, recently, Kadam et al. [69] grew crumpled sheet like RGO on CC through facile hydrothermal method without using any binder, which reduced contact resistance between current collector and active nanomaterials [68]. To investigated

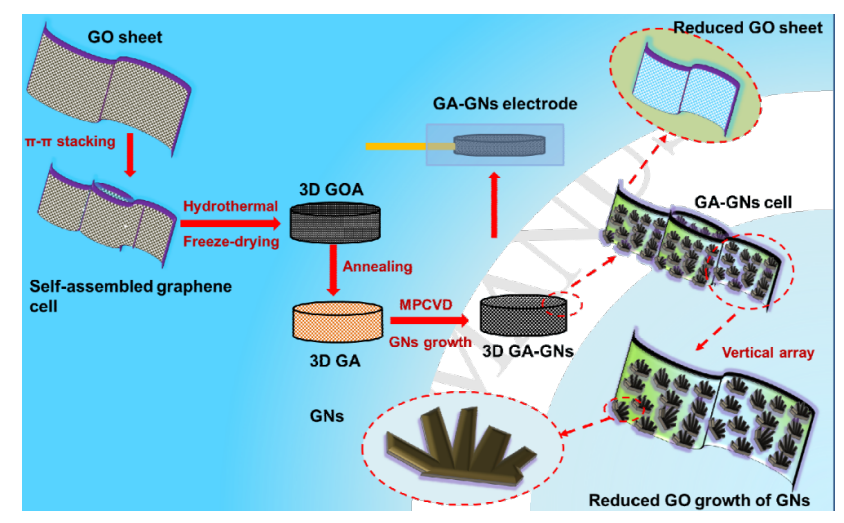

Figure 3: Schematic illustration of hierarchically microstructured 3D GA-GNs. The free-standing GA-GNs were fabricated by the microwave plasma chemical vapor deposition approach with a mechanically robust 3D GA framework as a template for GN growth. The GA was prepared by a modified hydrothermal method and subsequent freeze-drying process, and as-prepared GNs possess a orientation at nanoscale

its performance, RGO was prepared within a wide working temperature window $\left(120 \sim 200^{\circ} \mathrm{C}\right)$ with the step width of $20^{\circ} \mathrm{C}$. Moreover, RGO exhibited good long-term cycling stability, and the capacitance loss after 1000 cycles was only $3 \%$. Owing to these interesting structural, morphological and electrochemical properties, RGO grown on carbon cloth is considered as a promising electrode material for new generation of electrode based on carbon material for energy storage.

Zhang et al. [70] fabricated a 3D graphene-based nanostructure with graphene aerogel templating graphene nanosheets (GA-GNs) by an improved hydrothermal method and a microwave plasma chemical vapor deposition process. The schematic illustration of this 3D GAGNs was shown in Figure 3. GA-GNs exhibited a prominent electrical conductivity of $1000 \mathrm{~S} / \mathrm{m}$, which were promising candidates for high-performance supercapacitor electrodes. Moreover, this resulting free-standing and binderfree GA-GN presented a specific capacitance as high as 245 $\mathrm{F} \mathrm{g}^{-1}$, outstanding rate capability and desirable long-term cycling stability (92\% capacitance retention after 10000 cycles). Such an all-carbon electrode was used to fabricate a two-terminal symmetric solid supercapacitor, this supercapacitor shown favorable areal capacitance $\left(1.2 \mathrm{~F} \mathrm{~cm}^{-2}\right)$, low internal resistance and desirable long cycling stability (90\% capacitance retention after 5000 cycles). 


\section{Metal-oxide composites capacitors}

\section{1 $\mathrm{MnO}_{2}$-based composites capacitors}

Patil et al. [71] demonstrated a developed coaxial fibershaped asymmetric supercapacitor (CFASC), which addressed the obstacles of traditional fiber-shaped supercapacitor's low capacitance caused by its restricted surface area between two fiber electrodes and low energy density owing to the operating voltage range. Here, a gel electrolyte-coated core positive electrode was simply wrapped with the negative electrode, and $\mathrm{MnO}_{2}$ /CNT-web paper was employed as a cathode while $\mathrm{Fe}_{2} \mathrm{O}_{3}$ /carbon fiber was utilized as an anode. This simply and innovative design not only improved the flexibility and stability of the supercapacitor but also increased the operating potential window up to $2.2 \mathrm{~V}$, which realized the enhancement of the specific energy. Additionally, the assembled CFASC exhibited a volumetric capacitance up to $0.6 \mathrm{~F} \mathrm{~cm}^{-3}$ and revealed an energy density up to $0.43 \mathrm{mWh} \mathrm{cm}^{-3}$ with a power density of $0.02 \mathrm{~W} \mathrm{~cm}^{-3}$ at a $0.01 \mathrm{~A} \mathrm{~cm}^{-3}$ current. Furthermore, even after 10000 cycles, the capacitance retention of the CFASC could be $80 \%$. The excellent performance suggests CFASC as a promising candidate for fibershaped supercapacitor.

Jia et al. [72] reported a novel mesostructured CNT-on$\mathrm{MnO}_{2}$ nanosheet composite with a high weight percentage of $\mathrm{MnO}_{2}$, which was constructed by vertically aligned $\mathrm{MnO}_{2}$ nanosheets and in-situ formed oriented CNTs on $\mathrm{MnO}_{2}$ nanosheets. The fabrication process was shown in Figure 4. Due to the synergy effect, this assembly exhibited a high specific capacitance (up to $1229 \mathrm{~F} \cdot \mathrm{g}^{-1}$ ) and desirable long-term cycling stability (94.4\% capacitance retention after 100000 cycles). The fabrication of this $\mathrm{CNTs} / \mathrm{MnO}_{2}$ opens the door for preparing $\mathrm{MnO}_{2}$-CNT nanocomposites with a little weight percentage of carbons, which is a new step of energy storage materials.

Zhang et al. [73] reported ternary $\mathrm{rGO} / \mathrm{MnO}_{2} / \mathrm{CF}$ nanocomposites, which had a 3D hierarchical multihole architecture. Owing to the synergistic effect of $\mathrm{CF}$ conductive skeleton, pseudocapacitive of $\mathrm{MnO}_{2}$ and hierarchical porous structure jointly, specific capacitance of the composites reached up to $356.5 \mathrm{~F} \cdot \mathrm{g}^{-1}$ at a scan rate of $10 \mathrm{mV} \cdot \mathrm{s}^{-1}$. Furthermore, the hybrid of rGO helped prevent the exfoliation of $\mathrm{MnO}_{2}$ nanoparticles, so the resulting composites possessed a desirable long-term cycling stability $(93.6 \% \mathrm{ca}$ pacitance retention after 2000 cycles). The research firstly demonstrates the value of $\mathrm{CF}$ in potential application for high-performance supercapacitors. CF, derived from MP,

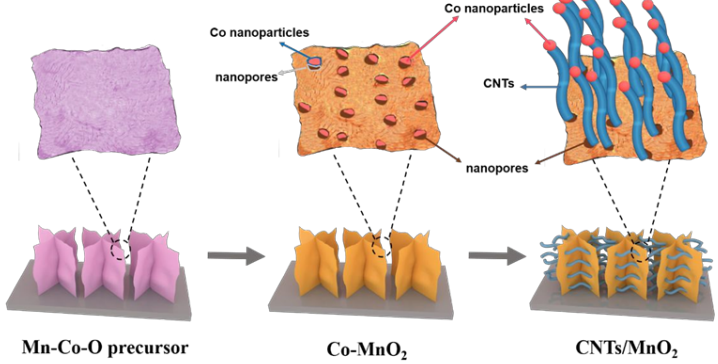

Figure 4: Through a hydrothermal process, $\mathrm{Mn}-\mathrm{Co}-\mathrm{O}$ precursor nanosheets have been vertically grown on Ni foam. Then, the precursors firstly transfer to metal $\mathrm{Co}$ embedded $\mathrm{MnO}_{2}$ nanosheets in low temperature, and further obtain tube-onsheet CNTs $/ \mathrm{MnO}_{2}$ nanocomposites by plasma enhanced chemical vapor deposition (PECVD) process

is expected to composite with $\mathrm{MnO}_{2}$ to apply on a broad range of emerging electrochemical supercapacitor.

Cakici et al. [74] firstly fabricated highly flexible carbon fiber fabric (CFF) filled with coral-like $\mathrm{MnO}_{2}$ structures via a green hydrothermal process at different conditions. Here, green hydrothermal method realized the assembly of CFF and coral-like $\mathrm{MnO}_{2}$ structures to improve the pseudocapacitance properties of the resulting $\mathrm{MnO}_{2} / \mathrm{CFF}$ composites, and CFF acted as an perfect template because it could both support substrate and reductant under the hydrothermal condition. subsequently, the composites were used as electrodes for electrochemical supercapacitors, Figure 5 shown the electrochemical properties of this device, this electrode material containing CFF, coated with coral-like $\mathrm{MnO}_{2}$ structures, obtained excellent specific capacitance (463 F. $\mathrm{g}^{-1}$ at $1 \mathrm{~A} \cdot \mathrm{g}^{-1}$ in a $1.0 \mathrm{M} \mathrm{Na}_{2} \mathrm{SO}_{4}$ electrolyte) and remarkable capacitance retention of $99.7 \%$ even after 5000 cycles. Moreover, this device revealed excellent stability and energy density $\left(20 \mathrm{~W} \mathrm{~h} \cdot \mathrm{kg}^{-1}\right)$.

Zhao et al. [75] synthesized a state-of-the-art hierarchical hollow nanostructure consisting of $\delta-\mathrm{MnO}_{2}$ nanosheets deposited by in-situ growth on hollow carbon nanofibers $\left(\mathrm{MnO}_{2} / \mathrm{HCNFs}\right)$ using the hydrothermal method and assembled them as an asymmetric supercapacitor (ASC) coin cell. Originating from its distinctive hollow structure, $\mathrm{MnO}_{2} / \mathrm{HCNFs}$ obtained $293.6 \mathrm{~F} \cdot \mathrm{g}^{-1}$ specific capacitance at $0.5 \mathrm{~A} \cdot \mathrm{g}^{-1}$ in $1 \mathrm{M} \mathrm{Na}_{2} \mathrm{SO}_{4}$ electrolyte, which was higher than non-hollow structure. When the high operating voltage window was up to $2 \mathrm{~V}$, this ASC cell held a $63.9 \mathrm{~F} \cdot \mathrm{g}^{-1}$ specific capacitance. Moreover, the asobtained ASC cell exhibited $35.1 \mathrm{Wh} \cdot \mathrm{kg}^{-1}$ high energy at $497.3 \mathrm{~W} \cdot \mathrm{kg}^{-1}$ power density and maximum $8.78 \mathrm{~kW} \cdot \mathrm{kg}^{-1}$ power density at $16.1 \mathrm{Wh} \cdot \mathrm{kg}^{-1}$ energy density with excellent stability. All of these demonstrated $\mathrm{MnO}_{2} / \mathrm{HCNFs}$ electrodes have stronger competition than $\mathrm{MnO}_{2} / \mathrm{SCNFs}$ elec- 

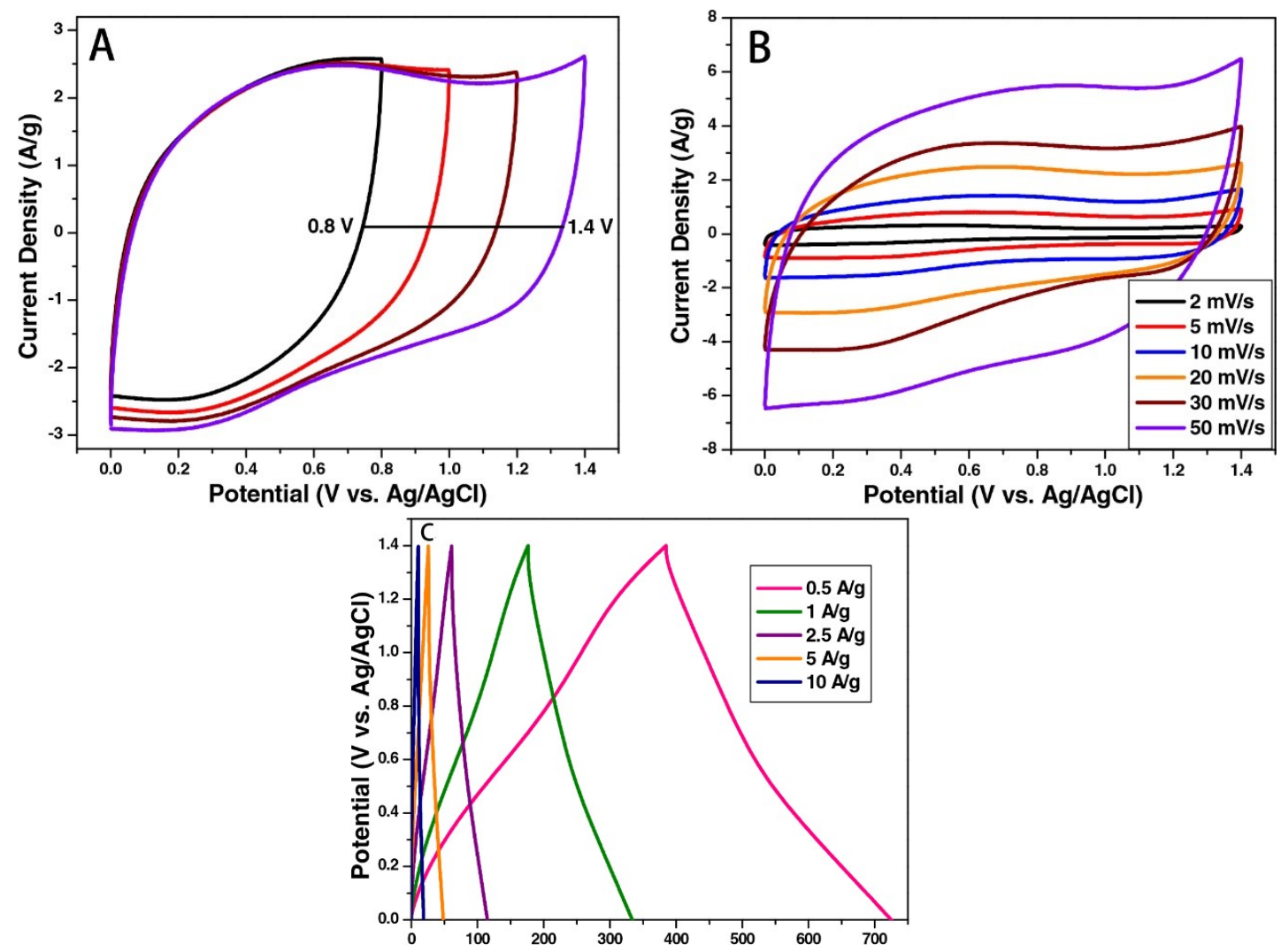

Figure 5: The electrochemical properties of the device were tested using two-electrode system for the $\mathrm{CFF} / \mathrm{MnO}_{2}$ composite that synthesized with $4 \mathrm{~h}$ reaction time. (A) CV curves of the device collected in different scan voltage windows, (B) CV curves at different scan rate, and (C) Ragone plots of the fabricated device

trodes in electrochemical properties, thus rational idea and manufacture of electrode materials with nanoarchitecture can help improve the use ratio of electro chemical active substances, thus greatly improving electrochemical performance.

\section{2 $\mathrm{TiO}_{2}$-based composites capacitors}

Recent, hydrogenated $\mathrm{TiO}_{2}$ has stimulated extensive research due to its low cost, high electrical conductivity, outstanding rate capability, and excellent stability. Herein, Pham et al. [76] fabricated hydrogenated $\mathrm{TiO}_{2} @$ @reduced graphene oxide (HTG) sandwich-like nanosheets, which were applied for high voltage and symmetric supercapacitors. The sandwich-like nanostructure was created by utilizing a sol-gel method of growing ultrafine $\mathrm{TiO}_{2}$ nanoparticles on the surface of GO sheets, even after hydrogenation, this special nanostructure remained. Nonetheless, with the increase of the hydrogenated $\mathrm{TiO}_{2}$ nanoparticles' diameter, the interval between the GO sheets was significantly changed, notably at a hydrogenation temperature of $500^{\circ} \mathrm{C}$. HTG revealed $51 \mathrm{~F} \cdot \mathrm{g}^{-1}$ specific capacitance at 1
$\mathrm{A} \cdot \mathrm{g}^{-1}$ and $82.5 \%$ capacitance retention. Furthermore, supercapacitors which were fabricated by HTG revealed desirable long-term cycling stability (80\% capacitance retention after 10000 cycles). These favorable properties indicate that HTG is such a great electrode material that can realize high-performance of supercapacitors.

Rice-like particle, which is one member of 1D nanostructure, can help enhance electron transport in the electrodes due to the short transport path. Liu et al. [77] successfully fabricated rice-like titanium oxide $\left(\mathrm{TiO}_{2}\right)$ /graphene hydrogel (RTGH) using a facile one-pot hydrothermal self-assembly method. Here, sodium citrate (SC), an environment-friendly coordination agent, was employed as a structure-directing agent. Owing to the covalent chemical bonding, there is a strong interaction between rice-like $\mathrm{TiO}_{2}$ nanoparticles and GNs, accordingly, in contrast to pristine graphene hydrogel (GH), P25/GH, and RTGH-blank, RTGH revealed excellent physicochemical properties, such as better adsorption capacities, specific capacitance and stability. For instance, RTGH obtained a high $372.3 \mathrm{~F} \mathrm{~g}^{-1}$ specific capacitance in the threeelectrode system and $332.6 \mathrm{~F} \mathrm{~g}^{-1}$ specific capacitance in 

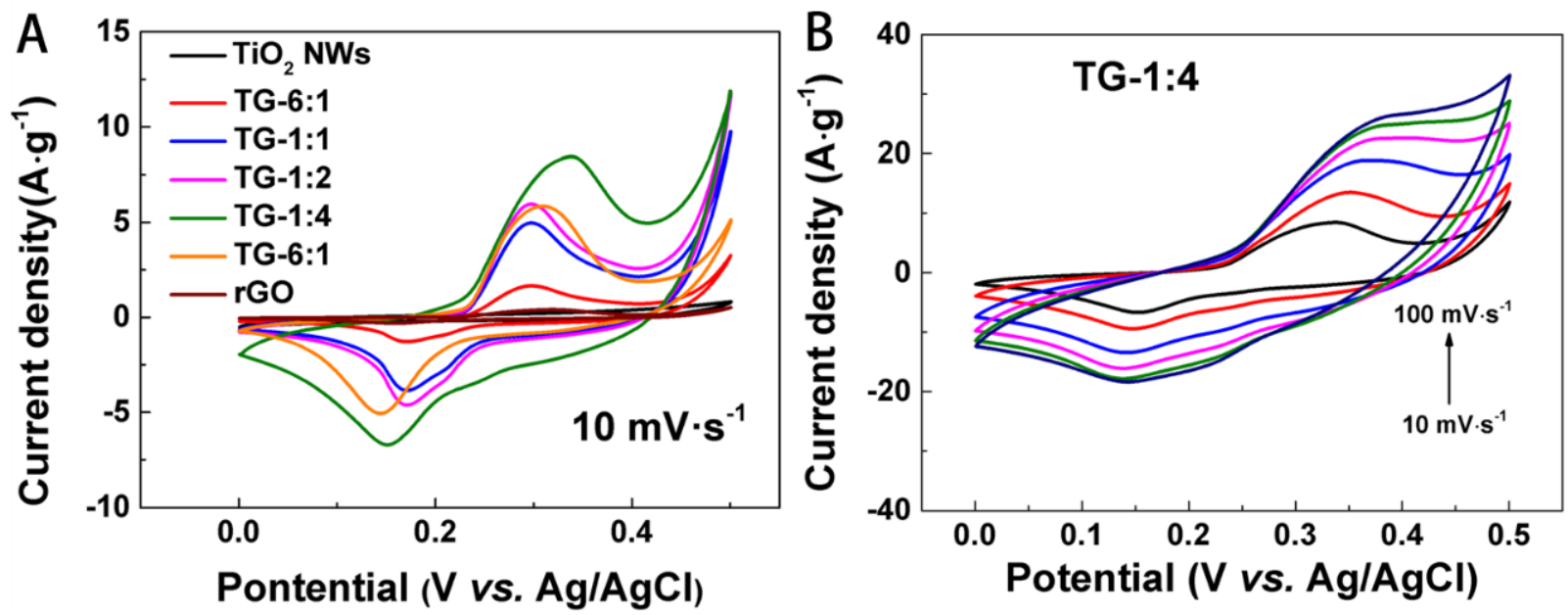

Figure 6: $\mathrm{CV}$ curves of the $\mathrm{TiO}_{2} \mathrm{NWs}, \mathrm{rGO}$, and $\mathrm{TiO}_{2} \mathrm{NWs}-\mathrm{rGO}$ nanocomposite. $\mathrm{A}$ : $\mathrm{rGO}, \mathrm{TiO}_{2} \mathrm{NWs}$, and $\mathrm{TiO}_{2} \mathrm{NWs}$-rGO nanocomposite with different initial mass ratios of $\mathrm{TiO}_{2}$ and $\mathrm{GO}$ at a scan rate of $10 \mathrm{mV} \mathrm{s}-1, \mathrm{~B}$ : TG-1:4 at various scan rates $\left(10,20,40,60,80\right.$, and 100 mV·s $\left.\mathrm{s}^{-1}\right)$

the two-electrode system at $0.2 \mathrm{~A} \mathrm{~g}^{-1}$ in $1 \mathrm{M} \mathrm{H}_{2} \mathrm{SO}_{4}$. Additionally, in the two-electrode mode, this RTGH had 91.4\% capacitance retention after 2000 cycles and favorable stability of $75.4 \%$ after 120 hours of floating test both at 4 $\mathrm{A} \cdot \mathrm{g}^{-1}$, consequently, this synthesis method can be further utilized to fabricate other metal oxide/carbon hybrid materials for supercapacitors.

Yue et al. [78] successfully assembled $\mathrm{TiO}_{2}$ nanowiresreduced $\mathrm{GO}\left(\mathrm{TiO}_{2}\right.$ NWs-rGO) nanocomposite via one-step hydrothermal synthesis. Initial mass ratio of $\mathrm{TiO}_{2} \mathrm{NPs}$ and $\mathrm{GO}$, which tremendously affected the morphologies and electrochemical properties of the synthesis, was investigated in detail. CV curves were shown in Figure 6, which revealed that when initial mass ratio of $\mathrm{GO}$ and $\mathrm{TiO}_{2} \mathrm{NPs}$ (with a length of approximately $10 \mu \mathrm{m}$ as well as a diameter of approximately $50 \mathrm{~nm}$ ) was 4:1, $\mathrm{TiO}_{2}$ NWs-rGO could obtain the best performance: this nanocomposite possessed $572 \mathrm{~F} \cdot \mathrm{g}^{-1}$ specific capacitance at a current density of 1 A. $\mathrm{g}^{-1}$ using $6 \mathrm{M} \mathrm{KOH}$ aqueous solution as electrolyte and a high rate capability with a capacitance retention ratio of approximately $84 \%$ after 5000 charge/discharge cycles at $10 \mathrm{~A} \cdot \mathrm{g}^{-1}$ (Figure 7 ). This research effort reveals that rational coupling some promising materials such $\mathrm{TiO}_{2}$ and rGO mentioned above can further enhance electrochemical performance of supercapacitor electrodes.

Microwave irradiation synthesis has been widely used in industries owing to its high efficiency, fast energy transfer and especially influence on the size, shape as well as morphology of the prepared material. Nagaraju et al. [79] synthesized a $\mathrm{TiO}_{2} /$ graphene nanocomposite via a facile, surfactant free, in-situ microwave irradiation route without any surfactant. The application of microwave irradiation not only made $\mathrm{TiO}_{2}$ nanoparticles distributed on the graphene sheet homogeneously, but also realized the reduction of graphene oxide to graphene. When applied on supercapacitor electrode, this nanocomposite obtained a higher specific capacitance value of $585 \mathrm{~F} \cdot \mathrm{g}^{-1}$ at $1 \mathrm{~A} \cdot \mathrm{g}^{-1}$ in 1 $\mathrm{M} \mathrm{H}_{2} \mathrm{SO}_{4}$ than $\mathrm{GO}\left(174 \mathrm{~F} \cdot \mathrm{g}^{-1}\right)$ and $\mathrm{TiO}_{2}$ electrode $\left(66 \mathrm{~F} \cdot \mathrm{g}^{-1}\right)$. Moreover, this composite exhibited a $14.25 \mathrm{Wh} \cdot \mathrm{kg}^{-1}$ energy density and $2.357 \mathrm{~kW} \cdot \mathrm{kg}^{-1}$ power density at $1 \mathrm{~A} \cdot \mathrm{g}^{-1}$. The excellent performance of this nanocomposite indicates that it will play an important role in next generation energy storage technology and microwave irradiation is such a low-cost, viable and simple method that can synthesize different metal oxide/graphene based composites and has a wide application in supercapacitors.

\section{Conducting polymers-carbon capacitors}

\subsection{Composite capacitors with CNTs}

Wang et al. [80] developed the flexible PANI-CNT@ZIF-67CC as supercapacitor electrode. Here, PANI was electrodeposited on CNT@ZIF-67/CC for the first time. The active materials were the PANI-CNT@ZIF-67 and flexible collector electrode was the flexible CC. After characterizing the obtained electrode, Figure 8 demonstrated that porous ZIF67 was enclosed by a mess of CNT and partial CNT went through the ZIF-67, which highly enhanced the electroconductivity of the electrode. Owing to the synergistic effect of PANI (including prominent electrical activity, desirable pseudo capacitance and favorable chemical doping/undoping) as well as CNT@ZIF-67-CC (covering large 

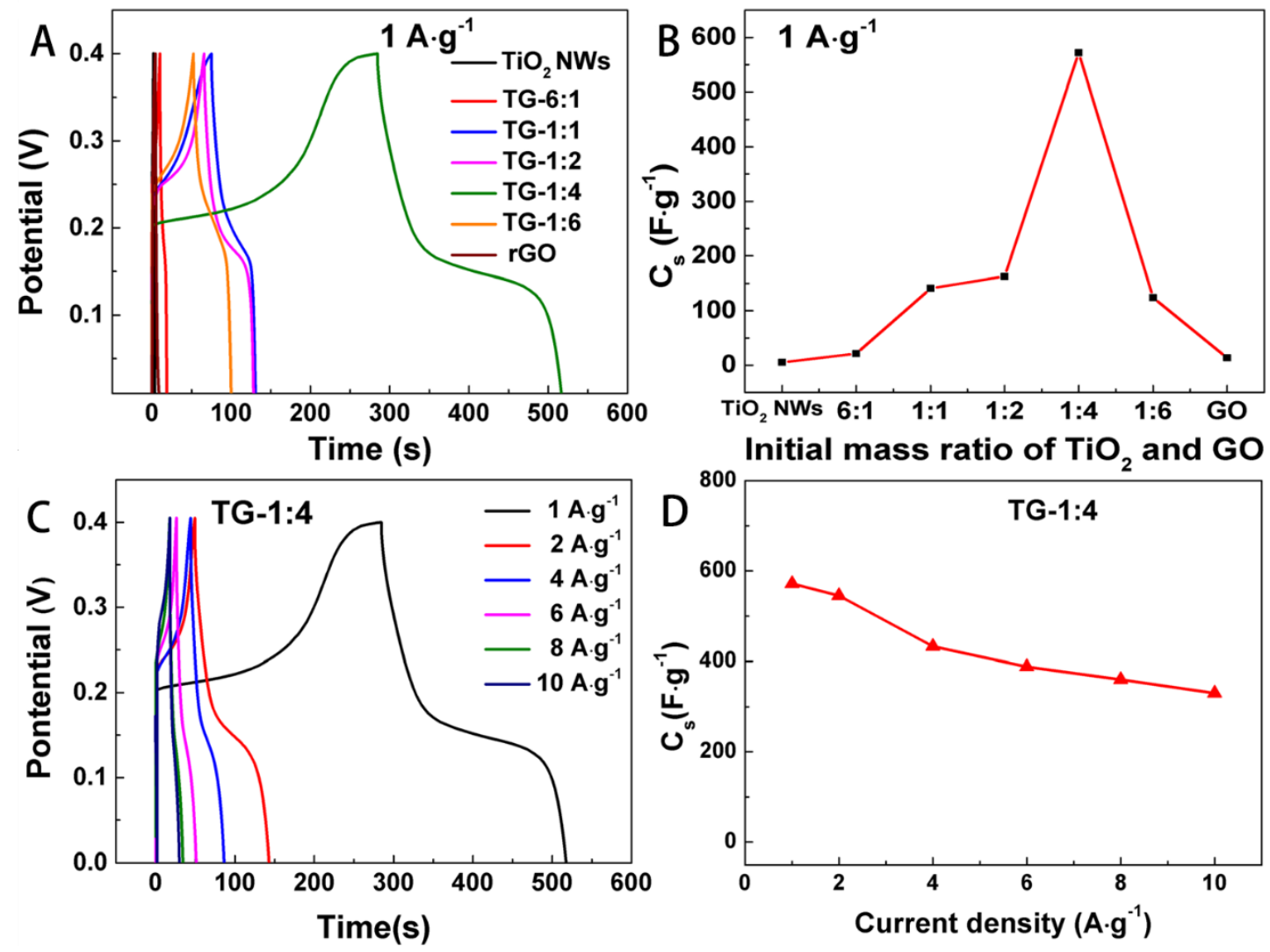

Figure 7: Electrochemical performance. $\mathrm{A}$ : $\mathrm{GCD}$ curves of the $\mathrm{TiO}_{2} \mathrm{NWs}-\mathrm{rGO}$ nanocomposites at $1 \mathrm{~A} \cdot \mathrm{g}^{-1}$. B: Specific capacitance of the TiO 2 NWs-rGO nanocomposites at $1 \mathrm{~A} \cdot \mathrm{g}^{-1}$. C: GCD curves of the TG-1:4 at various current densities. D: specific capacitances of the TG-1:4 at various current densities

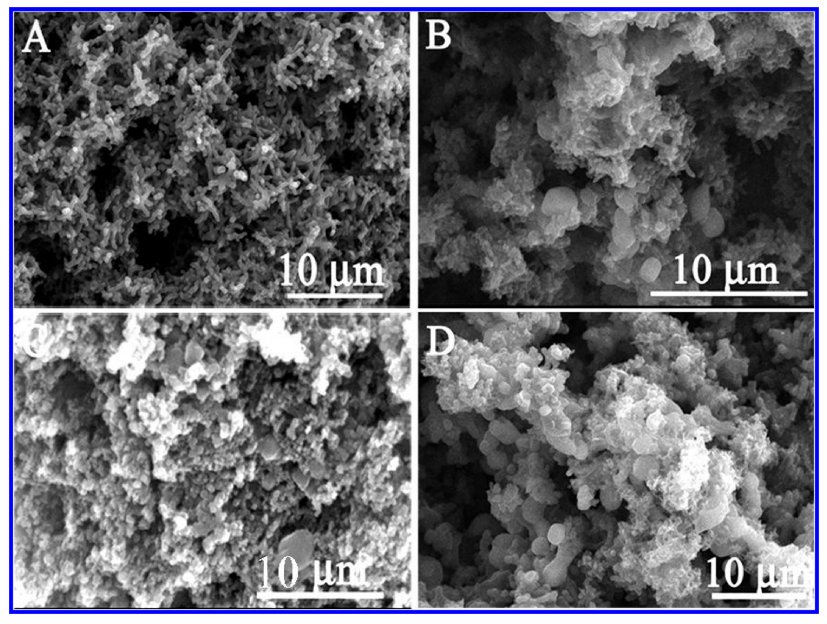

Figure 8: SEM images of (A) PANI-CC, (B) PANI-CNT@ZIF-67-CC, (C) ZIF-67-CC and (D) PANI-ZIF-67-CC

specific surface area, hierarchical porous nanostructures and outstanding electroconductivity), this synthetic PANICNT@ZIF-67-CC supercapacitor electrode held satisfying properties. The capacitance retention of this electrode could remain $83 \%$ even after 1000 cycles at $0.5 \mathrm{~mA} \cdot \mathrm{cm}^{-2}$, and specific capacitance was about $3511 \mathrm{mF} \cdot \mathrm{cm}^{-2}$.

Wang et al. [81] demonstrated three-dimensional nitrogen-doped porous activated carbon monoliths (3DNDP-ACMs) with regulative macro-mesopores and controllable morphologies through a two-step template-free route, which exhibited high capacitance properties as electrode materials. The preparation was shown in Figure 9, during thermal decomposition, the CNTs formed 3D-NDPACMs by shrinking the outer layer of PAN, thus providing additional pores. The overall characteristics of the 3D ordered porous structure and the high wettability of nitrogen functional groups could improve the surface utilization rate of carbon materials and facilitate the diffusion of ions in the electrolyte. The significant capacitive properties of this novel bulk material were due to the synergistic effect between conducting CNTs and the pseudo-capacitive behavior of pan derived nitrogen functional groups. These methods have universality and extensibility, and are suitable for the production of novel activated carbon monolithic materials extracted from polyimide, polyvinyl alcohol, cellulose and other polymers. 


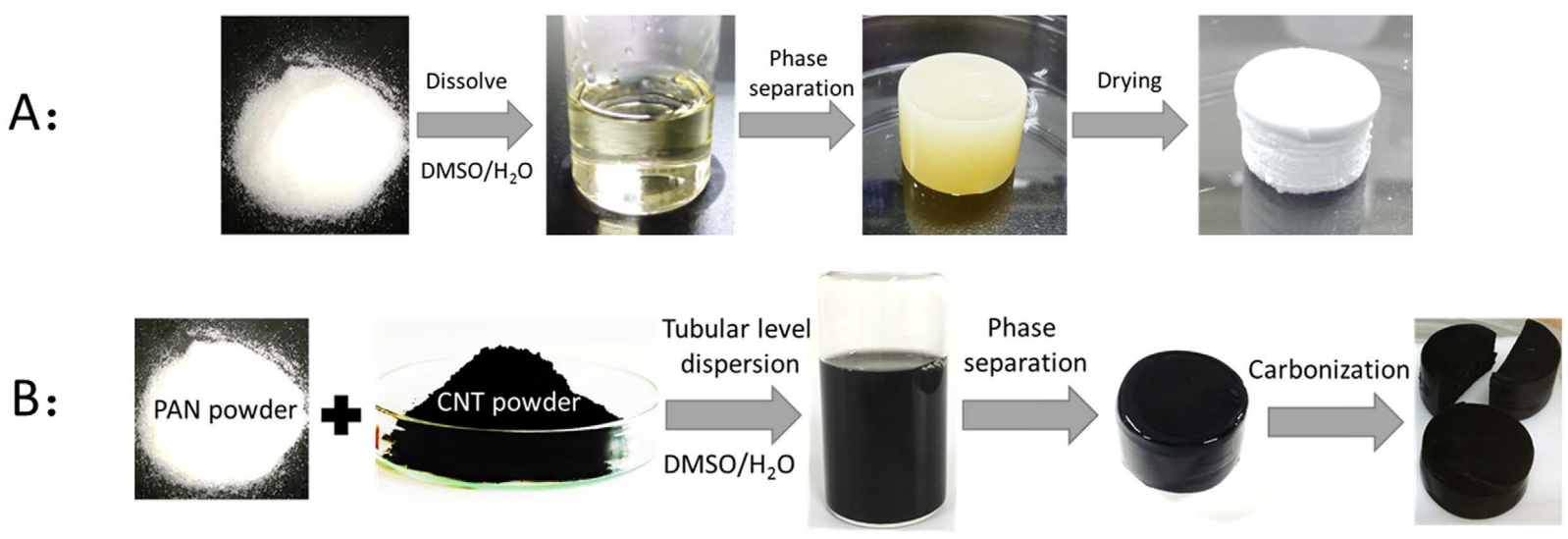

Figure 9: Preparation of typical three-dimensional (3D) hierarchical PAN (A) and PANCNT (B) monoliths

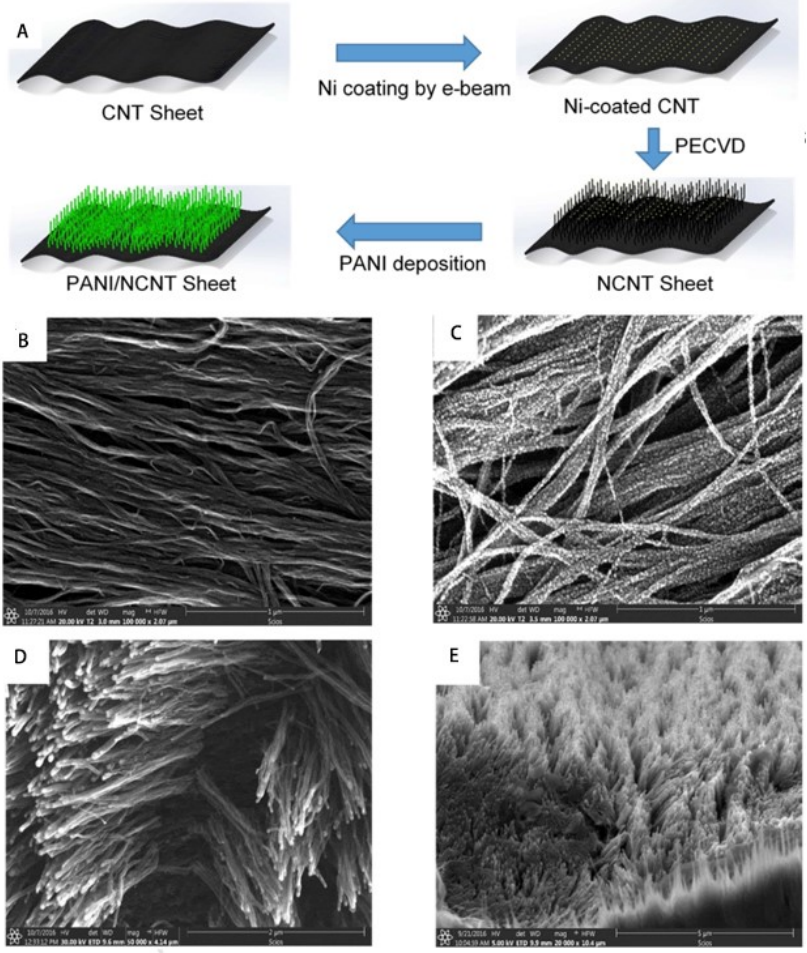

Figure 10: Schematic illustration of the process and SEM images of materials (A) Schematic illustration of the process. SEM images of (B) pristine CNT sheet. (C) Ni coated CNT sheet. (D) Vertically aligned CNT array grown on CNT sheet (NCNT). (E) NCNT sheet coated with polyaniline (30 cycles)

Jin et al. [82] constructed a three-dimension (3D) conductive network by CNTs and GNs on the polyester fabric via a "dipping-drying" process and electrophoretic deposition method, which significantly increased the electron transportation rate and reduced the electrolyte iondiffusion path. The resulting composite fabric provided a promising substrate for flexible supercapacitor's textilebased electrode preparation. When PANI was further coated on the surface of CNTs, the polyaniline/carbon nanotubes/graphene/polyester textile electrode revealed high electrochemical properties. At the current density of 1.5 $\mathrm{mA} \cdot \mathrm{cm}^{-2}$, the capacitance of the maximum area was 791 $\mathrm{mF} \mathrm{cm}{ }^{-2}$. Even after 3000 charge-discharge cycles, the capacitance retention rate of this composite electrode could still reach up to $76 \%$ in contrast to previously reported PANI electrodes with fast decay. In addition, the special electrode structure revealed strong stability under the mechanical bending and stretching conditions.

Recent developments in high-performance electrodes have created an interest in the development of various renewable energy storage systems. Malik et al. [83] utilized plasma enhanced chemical vapor deposition to synthesize vertically aligned CNT arrays on horizontally aligned CNT sheet for the first time. This innovative design combined excellent electrical conductivity and flexibility of CNT sheets with high surface area of CNT arrays. Electrodeposition of freestanding N-doped CNT(NCNT) sheets controlled deposition of polyaniline, thus enabled rapid charge transfer. In addition, The CNT core could offer reinforcement to the PANI coating, which obviously improved conductive polymer's long-term cycling stability. Figure 10a was the SEM image of NCNT sheet coated with polyaniline (30 cycles), and Figure 10b and 10c demonstrated NCNT maintained high capacitance and desirable long-term cycling stability, respectively.

\subsection{Composite capacitors with graphene}

Li et al. [84] prepared a novel 3D RGO/CNS/PANI ternary nanocomposite and employed them as supercapacitor electrode materials. Here, ammonium persulfate $\left(\left(\mathrm{NH}_{4}\right)_{2} \mathrm{~S}_{2} \mathrm{O}_{8}\right.$, APS) was added to a mixture of GO, aniline and CNS in an ice bath, and subsequently Zn powder 
was added to RGO to acquire RGO/CNS/PANI composites. During the reduction process from GO to RGO, the concomitant CNS was embedded between RGO nanosheets at the same time, effectively preventing RGO nanosheets from agglomerating as a "spacer". Specific capacitances of RGO, RGO/CNS, PANI, RGO/PANI and RGO/CNS/PANI at different current densities were shown in Figure 11, due to the excellent rate capability of EDL capacitors as well as high capacitance of pseudocapacitors from PANI $[85,86]$, the resulting RGO/CNS/PANI revealed the largest capacitance of all the tested composites. In addition, the capacity retention was $72 \%$ at $10 \mathrm{~A} \cdot \mathrm{g}^{-1}$ and after 1000 charge/discharge cycles, the capacity was $86 \%$. The preparation and capacitance application of ternary nanocomposites were reported for the first time, and this work reveal RGO/CNS/PANI ternary nanocomposites are one of the most promising materials for supercapacitor electrodes.

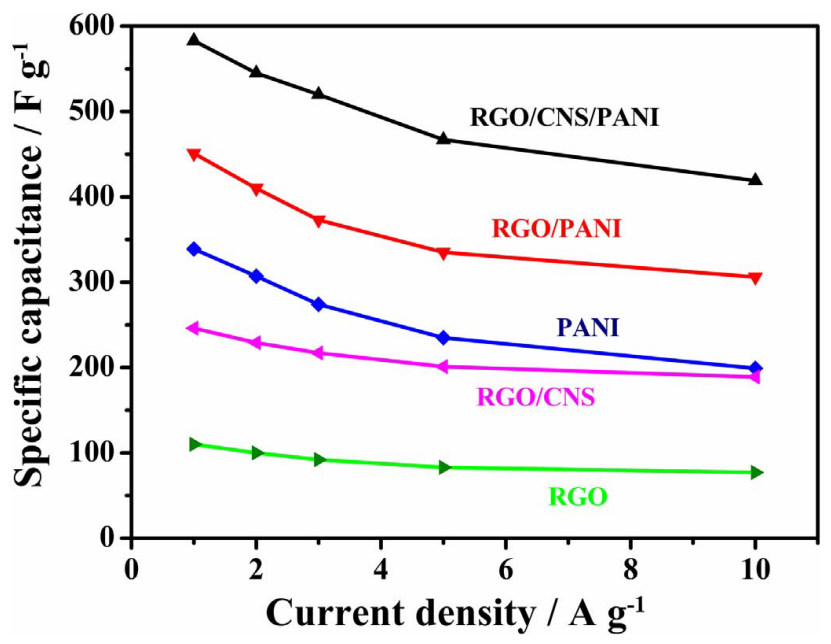

Figure 11: Specific capacitances of RGO, RGO/CNS, PANI, RGO/PANI and RGO/CNS/PANI at different current densities

Yu et al. [87] demonstrated a novel method to resultant graphene/polyaniline paper (GPp) and employed it as freestanding supercapacitor electrodes. The preparation process of GPp was demonstrated in Figure 12. Aniline pretreatment of GO in the first step was the key to grow high-density PANI nanoarrays onto GO nanosheets. During the process of sequent polymerization, GO nanosheets heterogeneously grew on surfaces and homogeneous grew in the solution, as a result, PANI nanoarrays and PANI nanofibers were fabricated, respectively. In the resultant GPp, PANI nanoarrays created a 3D network to guarantee GPp's self-supported, and PANI nanofibers constructed important pores and channels. This unique composite struc- ture not only optimizes the structure of PANI, but also highlights electron transfer and diffusion of electrolyte, which realized the excellent electrochemical performance of GPp electrode.

Wan et al. [88] demonstrated a facile scale-up process to fabricate a novel type of RGO/polypyrrole/cellulose (RPC). This RPC paper electrode obtained a low sheet resistance of $1.7 \Omega \cdot \mathrm{s} \cdot \mathrm{q}^{-1}$, a high areal capacitance of 1.20 $\mathrm{F} \cdot \mathrm{cm}^{-2}$ at a discharge current of $2 \mathrm{~mA} \mathrm{~cm}^{-2}$, desirable longterm cycling stability with a capacitance retain $89.5 \%$ after 5000 times cycles and prominent mechanical flexibility. In addition, an all-solid flexible layered SSC device prepared by RPC-2.5 and $\mathrm{H}_{3} \mathrm{PO}_{4} / \mathrm{PVA}$ gel electrolyte realized a high areal capacitance of $0.51 \mathrm{~F} \cdot \mathrm{cm}^{-2}$ and a superior energy density of $1.18 \mathrm{mWh} \mathrm{cm}^{-3}$ under the condition of $0.1 \mathrm{~mA} \cdot \mathrm{cm}^{-2}$. All of these results indicate that RPC-2.5 is suitable substance for the fabrication of multifarious highperformance supercapacitor with a high value of specific capacitance compared to several pure RGO.

Ensafi et al. [89] fabricated a thermally reduced graphene oxide/polymelamine formaldehyde nanocomposite (TRGO/PMF) by a polymerization method which was much simpler than previous methods for polymer synthesis [90, 91]. During the synthesis process, the added GO dispersed in the structure of the polymer and transformed to RGO, which resulted in an increase in the capacity and conductivity of PFM. Then, the performance of TRGO/PMF was evaluated, galvanostatic charge-discharge curves were shown in Figure 13, TRGO/PMF electrode obtained a specific capacitance of $2270 \mathrm{~F} \cdot \mathrm{g}^{-1}$ at $1.0 \mathrm{~A} \cdot \mathrm{g}^{-1}$. Additionally, Figure 14 manifested that the Bode phase angle plot was about $80^{\circ}$ at the tails, which was nearly an ideal capacitor. All of these results revealed TRGO/PMF holds great potential as a candidate electrode material.

\section{Conclusion}

This review summarizes the latest research on supercapacitor electrodes based on carbon materials. Carbon materials have been widely employed for fabricating SC electrodes owing to their satisfactory corrosion resistance, low density, excellent stability and low cost, and all-carbon composite materials can hold larger specific surface area and higher electrical conductivity. However, all-carbon materials reveal low power density and low cycling life. To overcome these defects, metal oxides are introduced, metal oxides are easy to synthesize and hold outstanding electrochemical properties. Hence, carbon materials are utilized as the scaffolds, metal oxides are deposited in situ 


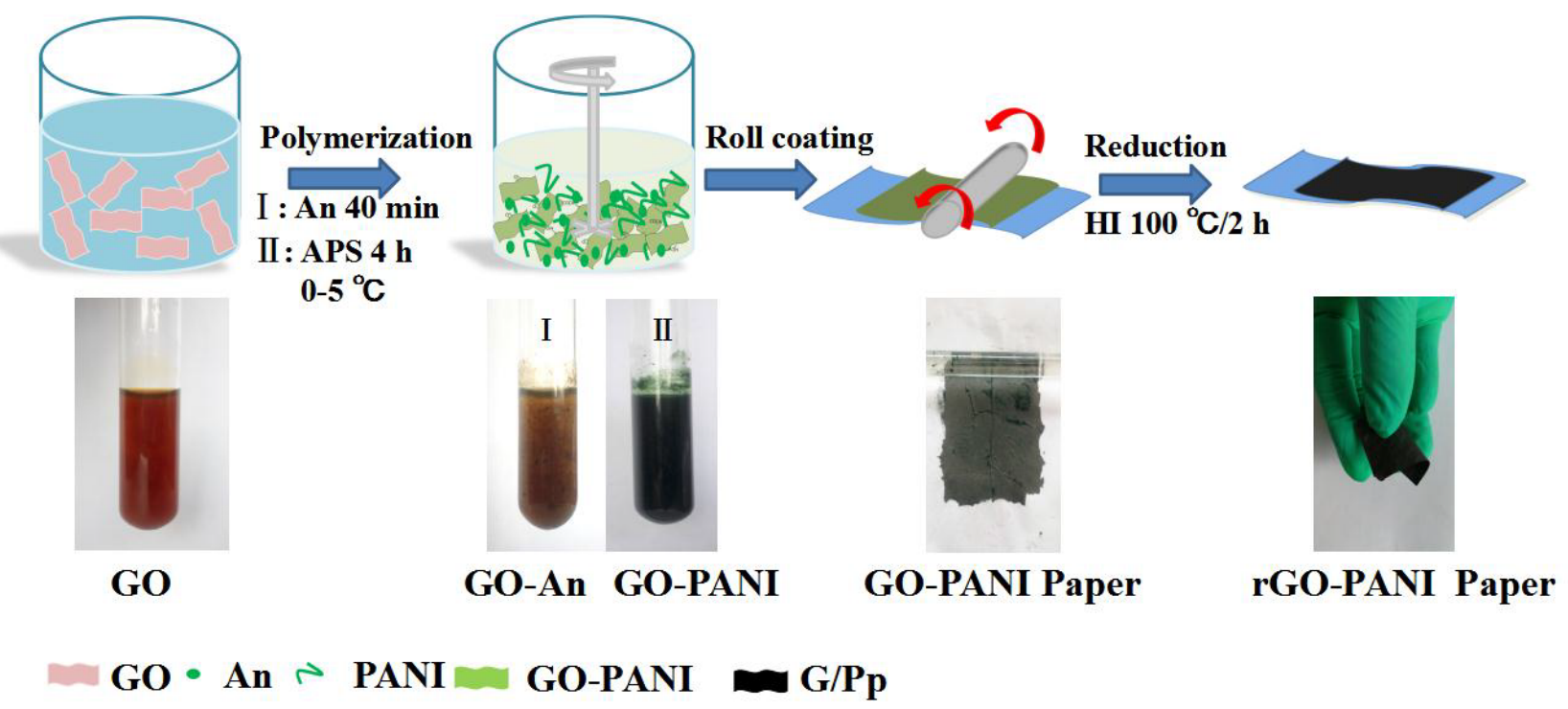

Figure 12: Preparation process of GPp
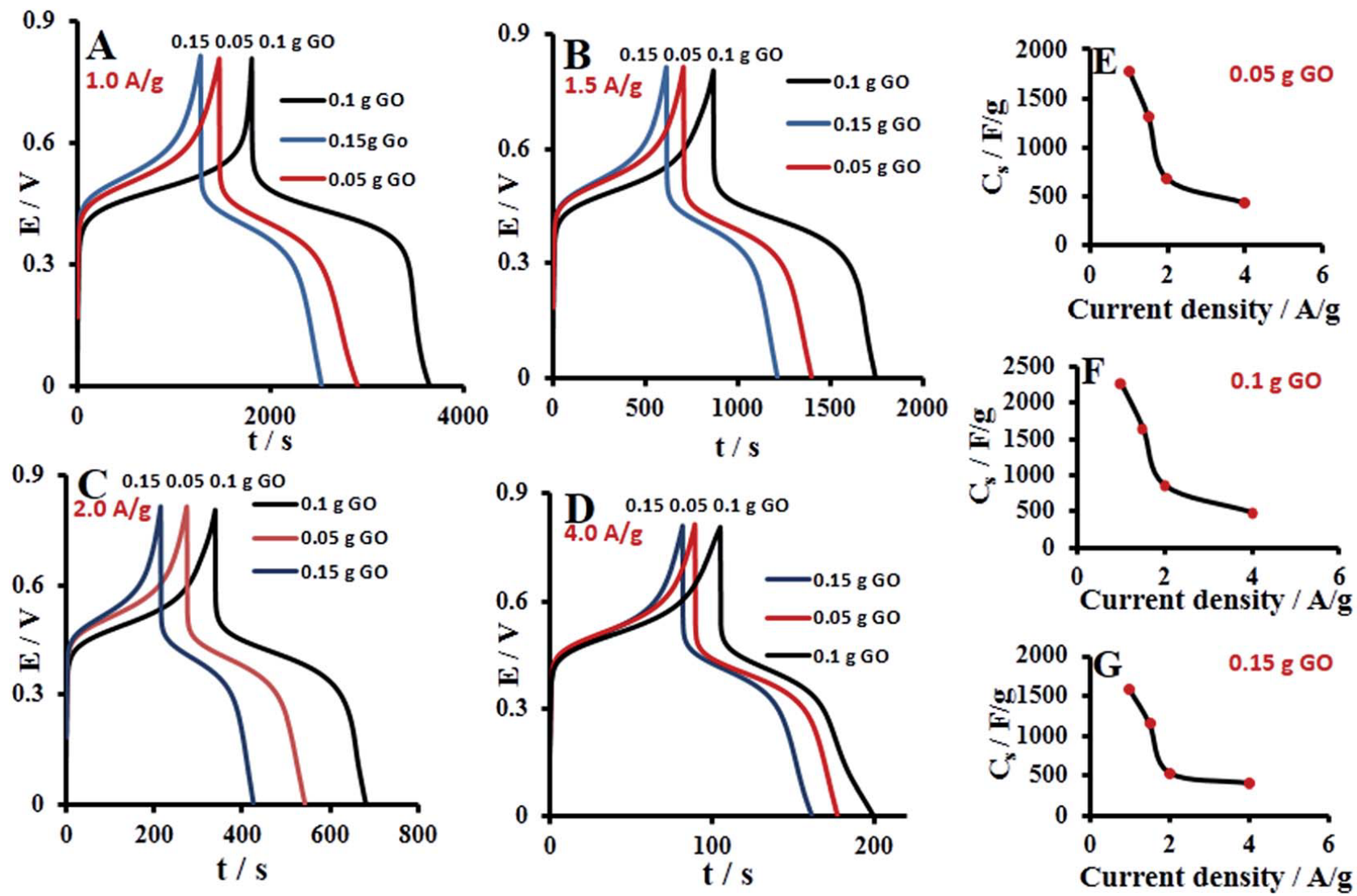

Figure 13: The GCD at current densities of (A) $1.0 \mathrm{~A} \cdot \mathrm{g}^{-1}$, (B) $1.5 \mathrm{~A} \cdot \mathrm{g}^{-1}$, (C) $2.0 \mathrm{~A} \cdot \mathrm{g}^{-1}$, and (D) $4.0 \mathrm{~A} \cdot \mathrm{g}^{-1}$ were obtained in the presence of various amounts of $\mathrm{GO}$; $(\mathrm{E})-(\mathrm{G})$ show the specific capacitance vs. the current density curves obtained from (A)-(D) 

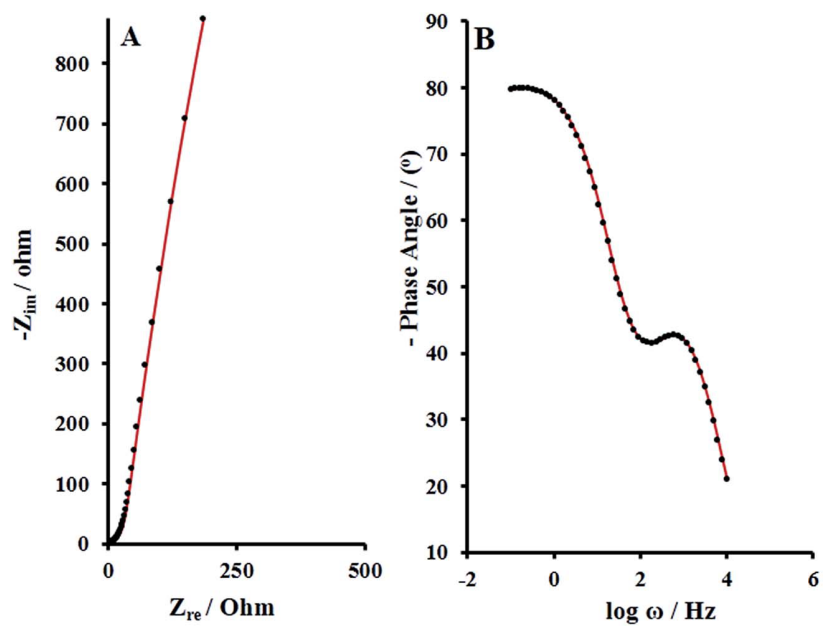

Figure 14: The Nyquist plot and Bode phase angle plot of the TRGO/PMF nanocomposite. A was the Nyquist plot and B was the Bode phase angle plot. EIS studies were performed in the frequency range from 0.1 to $100 \mathrm{kHz}$ and $\mathrm{OCP}$

on the surfaces of carbon materials. Furthermore, conducting polymer is another promising candidate for supercapacitor electrode, when compositing with carbon materials, drawbacks of pure PANI are solved, at the same time, the electroconductivity, thermal stability and specific capacitance are significantly improved. All of these results demonstrate that composite materials can improve the performance of supercapacitor electrodes that one single material never could.

However, there are still a number of riddles that need to be solved. It's no doubt that compositing carbon materials with other active basic will result in better performance of supercapacitors. In the future, carbon materials can be combined with other materials such as metal sulfides to find more application areas. We do hope this review will inspire more and more researchers to throw themselves into the fabrication of high performance supercapacitors to face the energy dilemma.

Acknowledgement: This work was supported by the National Nature Science Foundation of China (Grant Nos. 61604019, 11704263), and the National Natural Science Foundation of Liaoning (Grant Nos. 20170540748).

\section{References}

[1] Winter M, Brodd R. What are batteries, fuel cells, and supercapacitors? Chem. Rev. 2004, 104(10), 4245-4270

[2] Salunkhe R, Tang J, Kamachi Y, Nakato T, Kim J, Yamauchi Y. Asymmetric supercapacitors using 3D nanoporous carbon and cobalt oxide electrodes synthesized from a single metal-organic frame- work. ACS. Nano. 2015, 9(6), 6288-6296

[3] Holdren J. Energy and sustainability. Science. 2007, 315(5813), 737

[4] Wang H, Dai H. Strongly coupled inorganic-nano-carbon hybrid materials for energy storage. Chem. Soc. Rev. 2013, 42(7), 30883113

[5] Yu G, Xie X, Pan L, Bao Z, Cui Y. Hybrid nanostructured materials for high-performance electrochemical capacitors. Nano. Energy. 2013, 2(2), 213-234

[6] An K, Kim W, Park Y, Moon J, Bae D, Lim S, Lee Y, Lee Y. Electrochemical properties of high-power supercapacitors using singlewalled carbon nanotube electrodes. Adv. Funct. Mater. 2001, 11(5), 387-392

[7] Zhang Z, Xiao F, Qian L, Wang S, Liu Y. Facile synthesis of 3D $\mathrm{MnO}_{2}$-graphene and carbon nanotube-graphene composite networks for high-performance, flexible, all-solid-state asymmetric supercapacitors. Adv. Energy. Mater. 2014, 4(10), 1400064

[8] Wei W, Cui X, Chen W, Ivey D. Manganese oxide-based materials as electrochemical supercapacitor electrodes. Chem. Soc. Rev. 2011, 40(3), 1697-1721

[9] Hu C, Chang K, Lin M, Wu Y. Design and tailoring of the nanotubular arrayed architecture of hydrous $\mathrm{RuO}_{2}$ for next generation supercapacitors. Nano. Lett. 2006, 6(12), 2690-2695

[10] Ghodbane 0, Pascal J, Favier F. Microstructural effects on chargestorage properties in $\mathrm{MnO}_{2}$-based electrochemical supercapacitors. ACS. Appl. Mater. Inter. 2009, 1(5), 1130-1139

[11] Zhai Y, Dou Y, Zhao D, Fulvio P, Mayes R, Dai S. Carbon materials for chemical capacitive energy storage. Adv. Mater. 2011, 23(42), 4828-4850

[12] Dubal D, Ayyad O, Ruiz V, Gómez-Romero P, Hybrid energy storage: the merging of battery and supercapacitor chemistries. Chem. Soc. Rev. 2015, 44(7), 1777-1790

[13] Yu J, Lu W, Pei S, Gong K, Wang L, Meng L, Huang Y, Smith J, Booksh K, Li Q, Byun J, Oh Y, Yan Y, Chou T. Omnidirectionally stretchable high-performance supercapacitor based on isotropic buckled carbon nanotube films. ACS. Nano. 2016, 10(5), 52045211

[14] Lee J, Kim J, Hyeon T. Recent progress in the synthesis of porous carbon materials. Adv. Mater. 2006, 18(16), 2073-2094

[15] Chmiola J, Yushin G, Gogotsi Y, Portet C, Simon P, Taberna P. Anomalous increase in carbon capacitance at pore sizes less than 1 nanometer. Science. 2006, 313(5794), 1760-1763

[16] Kyotani T. Control of pore structure in carbon. Carbon 2000,38(2), 269-286

[17] Noked M, Avraham E, Bohadana Y, Soffer A, Aurbach D. Development of anion stereoselective, activated carbon molecular sieve electrodes prepared by chemical vapor deposition. J. Phys. Chem. C. 2009, 113(17), 7316-7321

[18] Lee J, Kim J, Hyeon T. Recent progress in the synthesis of porous carbon materials. Adv. Mater. 2006, 18(16), 2073-2094

[19] Hantel M, Kaspar T, Nesper R, Wokaun A, Kötz R. Partially reduced graphite oxide as an electrode material for electrochemical double-layer capacitors. Chem-Eur. J. 2012, 18(29), 9125-9136

[20] Hantel M, Kaspar T, Nesper R, Wokaun A, Kötz R. Partially reduced graphite oxide for supercapacitor electrodes: Effect of graphene layer spacing and huge specific capacitance. Electrochem. Commun. 2011, 13(1), 90-92

[21] Kuila T, Mishra A, Khanra P, Kim N, Lee J. Recent advances in the efficient reduction of graphene oxide and its application as energy storage electrode materials. Nanoscale. 2013, 5(1), 52-71 
[22] Wang Y, Shi Z, Huang Y, Ma Y, Wang C, Chen M, Chen Y. Supercapacitor devices based on graphene materials. J. Phys. Chem. C. 2009, 113(30), 13103-13107

[23] Hummers W, Offeman, R. (1958). Preparation of graphitic oxide. J. Am. Chem. Soc. 1958, 80(6), 1339-1339.

[24] Shin H, Kim K, Benayad A, Yoon S, Park H, Jung I, Jin M, Jeong $\mathrm{H}$, Kim J, Choi J, Lee Y. Efficient reduction of graphite oxide by sodium borohydride and its effect on electrical conductance. Adv. Funct. Mater. 2009, 19(12), 1987-1992

[25] Zhang W, Zhang Y, Tian Y, Yang Z, Xiao Q, Guo X, Jing L, Zhao Y, Yan $\mathrm{Y}$, Feng J, Sun K. Insight into the capacitive properties of reduced graphene oxide. ACS. Appl. Mater. Inter. 2014, 6(4), 2248-2254

[26] Pham V, Hur S, Kim E, Kim B, Chung J. Highly efficient reduction of graphene oxide using ammonia borane. Chem. Commun. 2013, 49(59), 6665-6667

[27] Liu Y, Zhang Y, Ma G, Wang Z, Liu K, Liu H. Ethylene glycol reduced graphene oxide/polypyrrole composite for supercapacitor. Electrochim. Acta. 2013, 88, 519-525

[28] Lei Z, Lu L, Zhao X. The electrocapacitive properties of graphene oxide reduced by urea. Energ. Environmental. Sci. 2012, 5(4), 6391-6399

[29] McAllister M, Li J, Adamson D, Schniepp H, Abdala A, Liu J, Herrera-Alonso M, Milius D, Car R, Prud'homme R, Aksay I. Single Sheet Functionalized Graphene by Oxidation and Thermal Expansion of Graphite. Chem. Mater. 2007, 19(18), 4396-4404

[30] Zhou Y, Bao Q, Tang L, Zhong Y, Loh K. Hydrothermal Dehydration for the "Green" Reduction of Exfoliated Graphene Oxide to Graphene and Demonstration of Tunable Optical Limiting Properties. Chem. Mater. 2009, 21(13), 2950-2956

[31] Yu H, He J, Sun L, Tanaka S, Fugetsu B. Influence of the electrochemical reduction process on the performance of graphenebased capacitors. Carbon. 2013, 51, 94-101

[32] Peng X, Liu X, Diamond D, Lau K. Synthesis of electrochemicallyreduced graphene oxide film with controllable size and thickness and its use in supercapacitor. Carbon. 2011, 49(11), 3488-3496

[33] Zhu Y, Murali S, Stoller M, Ganesh K, Cai W, Ferreira P, Pirkle A, Wallace R, Cychosz K, Thommes M, Su D, Stach E, Ruoff R. science. 2011, 332(6037), 1537-1541

[34] Brousse T, Bélanger D, Long J. (2015). To be or not to be pseudocapacitive? J. Electrochem. Soc. 2015, 162(5), A5185-A5189

[35] Kumar N, Huang C, Yen P, Wu W, Wei K, Tseng T. Probing the electrochemical properties of an electrophoretically deposited $\mathrm{Co}_{3} \mathrm{O}_{4} / \mathrm{rGO} / \mathrm{CNTs}$ nanocomposite for supercapacitor applications. RSC. Adv. 2016, 6(65), 60578-60586

[36] Chen W, Li Y, Han X, Zhao X, Zhao Y. Self-assembled $\mathrm{Co}_{9} \mathrm{~S}_{8} / \mathrm{RGO}$ CNT interconnected architecture as composite electrode for supercapacitors. RSC. Adv. 2017, 7(12), 6835-6841

[37] Bao W, Yu B, Li W, Fan H, Bai J, Ren Z. $\mathrm{Co}_{3} \mathrm{O}_{4} /$ nitrogen-doped graphene/carbon nanotubes: an innovative ternary composite with enhanced electrochemical performance. J. Alloy Compd. 2015, 647, 873-879

[38] Aboutalebi S, Chidembo A, Salari M, Konstantinov K, Wexler D, Liu H, Dou S. Comparison of GO, GO/MWCNTs composite and MWCNTs as potential electrode materials for supercapacitors. Energ. Environ. Sci. 2011, 4(5), 1855-1865

[39] Lee S, Nam G, Sun J, Lee J, Lee H, Chen W, Cho J, Cui Y. Enhanced intrinsic catalytic activity of $\lambda-\mathrm{MnO}_{2}$ by electrochemical tuning and oxygen vacancy generation. Angew. Chem. 2016, 128(30), $8741-8746$
[40] Zhang J, Jiang J, Zhao X. Synthesis and capacitive properties of manganese oxide nanosheets dispersed on functionalized graphene sheets. J. Phys. Chem. C. 2011, 115(14), 6448-6454

[41] Wang, X., Liu, X., \& Chen, K. (2016). Effect of different conductive additives on the electrochemical properties of mesoporous $\mathrm{MnO}_{2}$ nanotubes. Int. J. Electrochem. Sc. 2016, 11(8), 6808-6818

[42] Zhao P, Yao M, Ren H, Wang N, Komarneni S. Nanocomposites of hierarchical ultrathin $\mathrm{MnO}_{2}$ nanosheets/hollow carbon nanofibers for high-performance asymmetric supercapacitors. Appl. Surf. Sci. 2019, 463, 931-938

[43] Lee S, Kim J, Chen S, Hammond P, Shao-Horn Y. Carbon nanotube/manganese oxide ultrathin film electrodes for electrochemical capacitors. ACS. Nano. 2010, 4(7), 3889-3896

[44] Kim J, Khoh W, Wee B, Hong J. Fabrication of flexible reduced graphene oxide- $\mathrm{TiO}_{2}$ freestanding films for supercapacitor application. RSC. Adv. 2015, 5(13), 9904-9911

[45] Liu Y, Gao T, Xiao H, Guo W, Sun B, Pei M, Zhou G. One-pot synthesis of rice-like $\mathrm{TiO}_{2}$ /graphene hydrogels as advanced electrodes for supercapacitors and the resulting aerogels as high-efficiency dye adsorbents. Electrochim. Acta. 2017, 229, 239-252

[46] Nagaraju P, Alsalme A, Alswieleh A, Jayavel R. Facile in-situ microwave irradiation synthesis of $\mathrm{TiO}_{2} /$ graphene nanocomposite for high-performance supercapacitor applications. Electroanal. Chem. 2018, 808, 90-100

[47] Lu X, Hu Y, Wang L, Guo Q, Chen S, Chen S, Hou H, Song Y. Macroporous carbon/nitrogen-doped carbon nanotubes/polyaniline nanocomposites and their application in supercapacitors. Electrochim. Acta. 2016, 189, 158-165

[48] Hai Z, Gao L, Zhang Q, Xu H, Cui D, Zhang Z, Tsoukalas D, Tang J, Yan S, Xue C. Facile synthesis of core-shell structured PANI$\mathrm{Co}_{3} \mathrm{O}_{4}$ nanocomposites with superior electrochemical performance in supercapacitors. Appl. Surf. Sci. 2016, 361, 57-62

[49] Chi K, Zhang Z, Xi J, Huang Y, Xiao F, Wang S, Liu Y. Freestanding graphene paper supported three-dimensional porous graphenepolyaniline nanocomposite synthesized by inkjet printing and in flexible all-solid-state supercapacitor. ACS. Appl. Mater. Inter. 2014, 6(18), 16312-16319

[50] Camacho C, Mesquita J, Rodrigues J. Electrodeposition of polyaniline on self-assembled monolayers on graphite for the voltammetric detection of iron (II). Mater. Chem. Phys. 2016, 184, 261268

[51] Wang L, Lu X, Lei S, Song Y. Graphene-based polyaniline nanocomposites: preparation, properties and applications. J. Mater. Chem. A. 2014, 2(13), 4491-4509

[52] Babu K, Subramanian S, Kulandainathan M. Functionalisation of fabrics with conducting polymer for tuning capacitance and fabrication of supercapacitor. Carbohyd. Polym. 2013, 94(1), 487 . 495

[53] Lu X, Hu Y, Wang L, Guo Q, Chen S, Chen S, Hou H, Song, Y. Macroporous carbon/nitrogen-doped carbon nanotubes/polyaniline nanocomposites and their application in supercapacitors. Electrochim. Acta. 2016, 189, 158-165

[54] Kim B, Lee K, Kang S, Lee S, Pyo J, Choi I, Char K, Park J, Lee S, Lee J, Son J. 2D reentrant auxetic structures of graphene/CNT networks for omnidirectionally stretchable supercapacitors. Nanoscale. 2017, 9(35), 13272-13280

[55] Díez N, Botas C, Mysyk R, Goikolea E, Rojo T, Carriazo D. Highly packed graphene-CNT films as electrodes for aqueous supercapacitors with high volumetric performance. J. Mater. Chem. A. 2018, 6(8), 3667-3673 
[56] Li Y, Kang Z, Yan X, Cao S, Li M, Guo Y, Huan Y, Wen X, Zhang Y. A three-dimensional reticulate CNT-aerogel for a high mechanical flexibility fiber supercapacitor. Nanoscale. 2018, 10(19), 93609368

[57] Mehta R, Anderson D, Hager J. Graphitic open-celled carbon foams: processing and characterization. Carbon. 2003, 11(41), 2174-2176

[58] Wu X, Fang M, Mei L, Luo B. Preparation and characterization of carbon foams derived from aluminosilicate and phenolic resin. Carbon. 2011, 49(5), 1782-1786

[59] Tondi G, Fierro V, Pizzi A, Celzard A. Tannin-based carbon foams. Carbon. 2009, 47(6), 1480-1492

[60] Fan L, Hu Y, Maier J, Adelhelm P, Smarsly B, Antonietti M. High electroactivity of polyaniline in supercapacitors by using a hierarchically porous carbon monolith as a support. Adv. Funct. Mater. 2007, 17(16), 3083-3087

[61] Kumar R, Dhakate S, Saini P, Mathur R. Improved electromagnetic interference shielding effectiveness of light weight carbon foam by ferrocene accumulation. RSC. Adv. 2013, 3(13), 4145-4151

[62] Dang A, Li T, Xiong C, Zhao T, Shang Y, Liu H, Chen X, Li H, Zhuang $\mathrm{Q}$, Zhang S. Long-life electrochemical supercapacitor based on a novel hierarchically carbon foam templated carbon nanotube electrode. Compos. Part. B-Eng. 2018, 141, 250-257

[63] Shi K, Ren M, Zhitomirsky I. Activated carbon-coated carbon nanotubes for energy storage in supercapacitors and capacitive water purification. ACS. Sustain. Chem. Eng. 2014, 2(5), 12891298

[64] Xiong C, Li T, Zhao T, Shang Y, Dang A, Ji X, Li H, Wang J. Two-step approach of fabrication of three-dimensional reduced graphene oxide-carbon nanotubes-nickel foams hybrid as a binder-free supercapacitor electrode. Electrochim. Acta. 2016, 217, 9-15

[65] Li Z, Li Y, Wang L, Cao L, Liu X, Chen Z, Pan D, Wu M. Assembling Assembling nitrogen and oxygen co-doped graphene quantum dots onto hierarchical carbon networks for all-solid-state flexible supercapacitors. Electrochim. Acta. 2017, 235, 561-569

[66] Cheng Y, Lu S, Zhang H, Varanasi C, Liu J. Synergistic effects from graphene and carbon nanotubes enable flexible and robust electrodes for high-performance supercapacitors. Nano. Lett. 2012, 12(8), 4206-4211

[67] Zhu G, He Z, Chen J, Zhao J, Feng X, Ma Y, Fan Q, Wang L, Huang W. Highly conductive three-dimensional $\mathrm{MnO2-carbon} \mathrm{nanotube-}$ graphene-Ni hybrid foam as a binder-free supercapacitor electrode. Nanoscale. 2014, 6(2), 1079-85

[68] Wang S, Dryfe R. Graphene oxide-assisted deposition of carbon nanotubes on carbon cloth as advanced binder-free electrodes for flexible supercapacitors. J. Mater. Chem. A. 2013, 1(17), 52795283

[69] Kadam S, Kulkarni S. Influence of deposition temperature on physical and electrochemical properties of reduced graphene oxide electrode material for supercapacitor application. Ceram. Int. 2018, 44(12), 14547-14555

[70] Zhang Q, Wang Y, Zhang B, Zhao K, He P, Huang B. 3D superelastic graphene aerogel-nanosheet hybrid hierarchical nanostructures as high-performance supercapacitor electrodes. Carbon. 2018, 127, 449-458

[71] Patil B, Ahn S, Yu S, Song H, Jeong Y, Kim J, Ahn H. Electrochemical performance of a coaxial fiber-shaped asymmetric supercapacitor based on nanostructured $\mathrm{MnO}_{2}$ /CNT-web paper and $\mathrm{Fe}_{2} \mathrm{O}_{3}$ /carbon fiber electrodes. Carbon. 2018, 134, 366-375
[72] Jia H, Cai Y, Zheng X, Lin J, Liang H, Qi J, Cao J, Feng J, Fei W. Mesostructured carbon nanotube-on- $\mathrm{MnO}_{2}$ nanosheet composite for high-performance supercapacitors. ACS. Appl. Mater. Inter. 2018, 10(45), 38963-38969

[73] Zhang L, Li T, Ji X, Zhang Z, Yang W, Gao J, Li H, Xiong C, Dang A. Freestanding three-dimensional reduced graphene oxide/MnO2 on porous carbon/nickel foam as a designed hierarchical multihole supercapacitor electrode. Electrochim. Acta. 2017, 252, 306-314

[74] Cakici M, Kakarla R, Alonso-Marroquin F. Advanced electrochemical energy storage supercapacitors based on the flexible carbon fiber fabric-coated with uniform coral-like $\mathrm{MnO}_{2}$ structured electrodes. Chem. Eng. J. 2017, 309, 151-158

[75] Zhao P, Yao M, Ren H, Wang N, Komarneni S. Nanocomposites of hierarchical ultrathin $\mathrm{MnO}_{2}$ nanosheets/hollow carbon nanofibers for high-performance asymmetric supercapacitors. Appl. Surf. Sci. 2019, 463, 931-938

[76] Pham V, Nguyen-Phan T, Tong X, Rajagopalan B, Chung J, Dickerson J. Hydrogenated $\mathrm{TiO}_{2} @$ reduced graphene oxide sandwichlike nanosheets for high voltage supercapacitor applications. Carbon. 2018, 126, 135-144

[77] Liu Y, Gao T, Xiao H, Guo W, Sun B, Pei M, Zhou G. One-pot synthesis of rice-like $\mathrm{TiO}_{2} /$ graphene hydrogels as advanced electrodes for supercapacitors and the resulting aerogels as high-efficiency dye adsorbents. Electrochim. Acta. 2017, 229, 239-252

[78] Yue H, Guan E, Gao X, Yao F, Wang W, Zhang T, Wang Z, Song S, Zhang $\mathrm{H}$. One-step hydrothermal synthesis of $\mathrm{TiO}_{2}$ nanowiresreduced graphene oxide nanocomposite for supercapacitor. Ionics. 2018, 1-8

[79] Nagaraju P, Alsalme A, Alswieleh A, Jayavel R. Facile in-situ microwave irradiation synthesis of $\mathrm{TiO}_{2} /$ graphene nanocomposite for high-performance supercapacitor applications. J. Electroanal. Chem. 2018, 808, 90-100

[80] Wang L, Yang H, Pan G, Miao L, Chen S, Song Y. PolyanilineCarbon Nanotubes@ Zeolite Imidazolate Framework67-Carbon Cloth Hierarchical Nanostructures for Supercapacitor Electrode. Electrochim. Acta. 2017, 240, 16-23

[81] Wang Y, Fugetsu B, Wang Z, Gong W, Sakata I, Morimoto S, Hashimoto Y, Endo M, Dresselhaus M, Terrones M. Nitrogendoped porous carbon monoliths from polyacrylonitrile (PAN) and carbon nanotubes as electrodes for supercapacitors. Sci. Rep-UK. 2017, 7, 40259

[82] Jin L, Shao F, Jin C, Zhang J, Liu P, Guo M, Bian S. Highperformance textile supercapacitor electrode materials enhanced with three-dimensional carbon nanotubes/graphene conductive network and in situ polymerized polyaniline. Electrochim. Acta. 2017, 249, 387-394

[83] Malik R, Zhang L, McConnell C, Schott M, Hsieh Y, Noga R, Alvarez N, Shanov V. Three-dimensional, free-standing polyaniline/carbon nanotube composite-based electrode for highperformance supercapacitors. Carbon. 2017, 116, 579-590

[84] Li R, Xu H, Fu R, Tan W, Qin Y, Tao Y, Kong Y. Preparation of $3 \mathrm{D}$ reduced graphene oxide/carbon nanospheres/polyaniline ternary nanocomposites as supercapacitor electrode. React. Funct. Polym. 2018, 125, 101-107

[85] Gao Z, Wang F, Chang J, Wu D, Wang X, Wang X, Xu F, Jiang K. Chemically grafted graphene-polyaniline composite for application in supercapacitor. Electrochim. Acta. 2014, 133, 325-334

[86] Rudge A, Davey J, Raistrick I, Gottesfeld S, Ferraris J. Conducting polymers as active materials in electrochemical capacitors. J. 
Power. Sources. 1994, 47(1-2), 89-107

[87] Yu H, Ge X, Bulin C, Xing R, Li R, Xin G, Zhang B. Facile fabrication and energy storage analysis of graphene/PANI paper electrodes for supercapacitor application. Electrochim. Acta. 2017, 253, 239 . 247

[88] Wan C, Jiao Y, Li J. Flexible, highly conductive, and free-standing reduced graphene oxide/polypyrrole/cellulose hybrid papers for supercapacitor electrodes. J. Mater. Chem. A. 2017, 5(8), 38193831

[89] Ensafi A, Alinajafi H, Rezaei B. Thermally reduced graphene oxide/polymelamine formaldehyde nanocomposite as a high specific capacitance electrochemical supercapacitor electrode. J. Mater. Chem. A. 2018, 6(14), 6045-6053
[90] Kaverlavani S, Moosavifard S, Bakouei A. Designing graphenewrapped nanoporous $\mathrm{CuCO}_{2} \mathrm{O}_{4}$ hollow spheres electrodes for high-performance asymmetric supercapacitors. J. Mater. Chem. A. 2017, 5(27), 14301-14309

[91] Moosavifard S, Shamsi J, Altafi M, Moosavifard Z. All-solid state, flexible, high-energy integrated hybrid micro-supercapacitors based on 3D LSG/CoNi $\mathrm{S}_{4}$ nanosheets. Chem. Commun. 2016, 52(89), 13140-13143 